\title{
RADIOCHEMICAL STUDIES OF THE SORPTION BEHAVIOR OF STRONTIUM AND BARIUM
}

\author{
H. GÖKTÜRK, ${ }^{1}$ C. EYLEM, ${ }^{1,2}$ S. HATIPOĞLU, ${ }^{1}$ H. N. ERTEN ${ }^{2}$ \\ ${ }^{1}$ Department of Chemistry, Middle East Technical University, 06531 Ankara (Turkey) \\ ${ }^{2}$ Department of Chemistry, Bilkent University, 06533 Ankara (Turkey)
}

(Received July 24, 1995)

\begin{abstract}
The sorption behavior of strontium and barium on kaolinite, bentonite and chlorite-illite mixed clay was studied by radioanalytical techniques using the batch method. ${ }^{90} \mathrm{Sr}(29.1 \mathrm{y})$ and ${ }^{133} \mathrm{Ba}(10.5 \mathrm{y})$ were used as radiotracers. Characterization of the solid matrices was done by FTIR and XRD spectrometries and specific surface area measurements. Synthetic groundwater was used as the aqueous phase. The variation of the distribution ratio $R_{d}$, as a function of metal ion loading was examined. The sorption isotherms were fitted to various isotherm models. The sorption energies were calculated to be in the range of $8-10 \mathrm{~kJ} / \mathrm{mol}$ suggesting an ion exchange type of sorption mechanism. In detailed experiments, chlorite-illite mixed clay was first presaturated with $\mathrm{K}^{+}, \mathrm{Sr}^{2+}, \mathrm{Ca}^{2+}$ and $\mathrm{Al}^{3+}$ ions, respectively, prior to sorption studies with $\mathrm{Ba}^{2+}$ ions. The results of $\mathrm{Ca}^{2+}$ pretreated chlorite-illite were very similar to those of natural chlorite-illite, suggesting that the $\mathrm{Ba}^{2+}$ ion exchanges primarily with the $\mathrm{Ca}^{2+}$ ion on the clay minerals.
\end{abstract}

The sorption of waste radionuclides on to soil constituents, particularly on clay minerals act as a barrier to their dispersion by the groundwater. Many investigations on radionuclide migration and their sorption behavior have been carried out. ${ }^{1-11}$ The general objective was to understand the effects of different parameters such as composition of groundwater, its $\mathrm{pH}$, structure of solid matrix on the sorption process as well as to establish a basis for the modelling and prediction of radionuclide behavior in the geological environment.

In this work the sorption behavior of $\mathrm{Sr}^{2+}$ and $\mathrm{Ba}^{2+}$ cations were studied. The results would contribute to the establishment of a data base for migration models. Furthermore, since strontium and barium are homologs of important species radium, their results could provide information about the migration behavior of radium. 


\section{Experimental}

Minerals: The kaolinite, bentonite and chlorite-illite minerals used in the sorption experiments were obtained from the Mineral Research and Exploration Institute (M.T.A.). Their compositions and structural characterizations were studied by surface area measurements, FTIR, XRD and differential thermal gravimetric analysis (DTGA).

Surface area measurements were done by using a Quantosorb Surface Area Analyzer with nitrogen gas as adsorbate and helium as carrier gas. A Nicolet DX Model FTIR spectrometer and JEOL JSDX-100S diffractometer with Ni filtered CuK radiation were used in FTIR and XRD studies. DTGA was carried out using a Mettler TA-300 Thermal Analyzer. The particle size of the solid matrices used were less than 38 mesh. The surface areas determined by the BET isotherm technique were $9.20 \mathrm{~m}^{2} / \mathrm{g}$ for kaolinite and $115.5 \mathrm{~m}^{2} / \mathrm{g}$ for the bentonite clays. The kaolinite clay consisted mostly of kaolinite and quartz minerals with a small amount of mica whereas bentonite clay consisted of montmorillonite and quartz minerals. Chlorite-illite mixed clay was mostly chlorite clay with a small amount of smectite. The experimental CEC of the kaolinite, bentonite and chlorite-illite clays, determined by the Silver-Thiourea method ${ }^{12}$ were found as 6,21 and $15 \mathrm{meq} / 1000 \mathrm{~g}$, respectively.

Synthetic groundwater ( $S G W$ ): The experiments were carried out using synthetic groundwater with a composition given in Table 1.

Table 1

Composition of the synthetic groundwater used in experiments, $\mathrm{pH} 7.80$

\begin{tabular}{lcccccc}
\hline \multicolumn{7}{c}{ Ion concentration, meq/ml } \\
\hline $\mathrm{Na}^{+}+\mathrm{K}^{+}$ & $\mathrm{Ca}^{2+}$ & $\mathrm{Mg}^{2+}$ & $\mathrm{CO}_{3}^{2-}$ & $\mathrm{NO}_{3}^{-}$ & $\mathrm{Cl}^{-}$ & $\mathrm{SO}_{4}^{2-}$ \\
0.89 & 4.70 & 3.15 & 0.17 & 3.14 & 0.84 & 0.18 \\
\hline
\end{tabular}

In the SGW, the bicarbonate species was largely replaced by nitrate ions because carbonate species are not in equilibrium with the atmospheric $\mathrm{CO}_{2}$ in groundwaters.

Radiotracers: The radionuclides ${ }^{90} \mathrm{Sr}(29.1 \mathrm{y})$ and ${ }^{133} \mathrm{Ba}(10.5 \mathrm{y})$ were used as tracers. They were obtained from the Radiochemical Center - Amersham. According to the supplier's information their activities were $5 \mathrm{mCi} / \mathrm{ml}\left({ }^{90} \mathrm{Sr}\right)$ and $0.1 \mathrm{mCi} / \mathrm{ml}\left({ }^{133} \mathrm{Ba}\right)$ and concentrations $50 \mathrm{~g} / \mathrm{ml}$ and $24 \mathrm{~g} / \mathrm{ml}$, respectively.

Sorption procedure: All serption experiments were carried out in duplicate. About $100 \mathrm{mg}$ of the solid matrix was added to each precleaned and dried polypropylene centrifuge tube and weighed. $10 \mathrm{ml}$ of SGW was added to each tube and shaken for 4 days at $250 \mathrm{rpm}$ using a lateral shaker. The samples were 
than centrifuged for 30 minutes at $5700 \mathrm{rpm}$ and the liquid phases were discarded. After this preequilibration step the tubes were weighed again and $5 \mathrm{ml}$ of SGW containing radiotracer and the desired cation concentration were added. The samples were shaken for about 8 days during which time sorption equilibrium was assumed. After centrifugation an aliquot of the liquid phase was counted for ${ }^{133} \mathrm{Ba}$ activity using a HPGe detector. In the case of ${ }^{90} \mathrm{Sr}, 1 \mathrm{ml}$ of active solution was introduced onto a planchet, dried and counted using a Geiger-Müller counter. Initial liquid phase activities before shaking were counted under the same conditions. The appropriate equations used in the distribution ratio, $R_{d}$, calculations from the measured initial and final liquid phase activities, are given in Reference 6. Sorption on the polypropylene tube walls was tested by shaking samples without solid matrix and comparing the activities before and after shaking. No sorption on the walls of the centrifuge tubes was detected.

\section{Results and discussion}

The distribution ratio, $R_{d}$, expressing the results of sorption experiments represent time equilibrium conditions. As such it is a function of factors such as temperature and $\mathrm{pH}$. It is, however, often a function of the initial ion concentration. The variation of the distribution ratio with initial concentration at constant temperature is described by various isotherm models. Three of these are most frequently used in sorption experiments: Langmuir, Freundlich and Dubinin-Radushkevich type isotherms. ${ }^{13-15}$ The last two isotherms may be represented by the relations;

$$
\begin{gathered}
C_{s}=K C_{l}^{N} \\
C_{s}=C_{s}^{0} e^{-k E}
\end{gathered}
$$

respectively, where

$C_{s}$ - the amount of sorbed solute on solid matrix (meq/g),

$C_{l}$ - equilibrium solute concentration in solution (meq/g), $k, N, K$ - constants,

$C_{s}^{0}=$ sorption capacity (meq/g),

$E=R T \ln \left(1+1 / C_{)}\right)$,

$R$ - gas constant,

$T$ - temperature (K). 
The distribution ratio, $R_{d}$, is related to the isotherm equations by the relationships:

$$
\begin{gathered}
R_{d}=K C_{l}^{N-1} \\
R_{d}=\left(C_{s}^{0} / C_{l}\right) e^{-k\left(R T \ln \left(1+1 / C_{l}\right)\right)} .
\end{gathered}
$$

Once the isotherm constants are experimentally determined. Eqs (3) and (4) may be used to calculate $R_{d}$ values as a function of solute ion concentration in solution. If $N$ in Eq. (3) equals to one, $R_{d}$ becomes equal to the constant $K$ and the isotherm is termed as linear; i.e., $R_{d}$ does not change with initial solute concentration.

The results of isotherm fits to the experimental data are given in Table 2 . The sorption energies were calculated using the Dubinin-Radushkevich constant $k$ from the relation

$$
\text { Sorption energy }=(2 k)^{-1 / 2} \text {. }
$$

It is found that bentonite clay is a better sorbing matrix than kaolinite. The chlorite-illite mixed clay being as good as bentonite. The Freundlich constant $N$ is close to unity in all cases. However, the isotherms are not quite linear. Both Freundlich and Dubinin-Radushkevich type isotherms fit the experimental data very well (correlation coefficient $=0.99$ ). Fits to Langmuir isotherms were poor in all cases.

The sorption energies determined are all within the range of ion exchange type reactions $(8-16 \mathrm{~kJ} / \mathrm{mole})$.

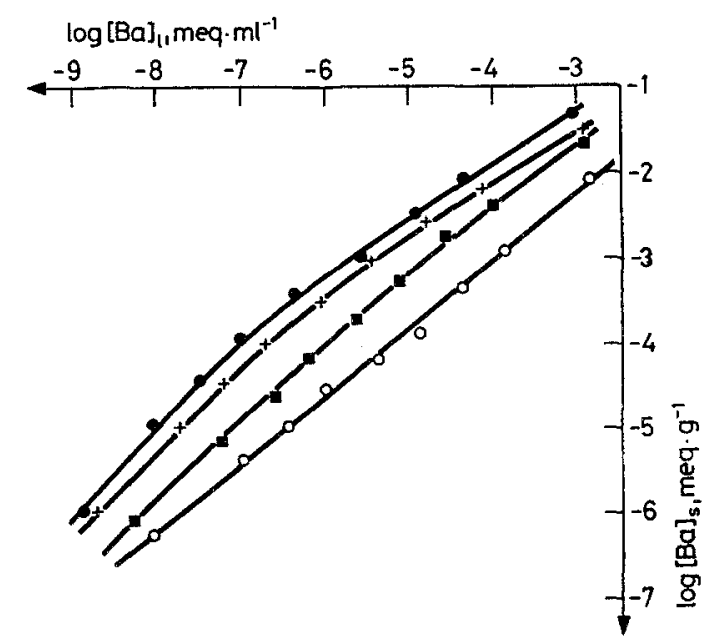

Fig. 1. Sorption isotherms of $\mathrm{Ba}^{2+}$ ion sorption on chloride-illite mixed clay; $\mathrm{K}$-saturated chlorite-illite, + Ca-saturated chlorite-illite, $\mathbf{m}$-saturated chlorite-illite, O Al-saturated chlorite-illite 
Table 2

Isotherm constants for the sorption of $\mathrm{Ba}^{2+}$ and $\mathrm{Sr}^{2+}$ on kaolinite, bentonite and chlorite - illite clays

\begin{tabular}{|c|c|c|c|c|c|c|c|}
\hline \multirow{3}{*}{$\begin{array}{l}\text { Sorbed } \\
\text { ion }\end{array}$} & \multirow{3}{*}{ Matrix } & \multicolumn{4}{|c|}{ Isotherm } & \multirow{3}{*}{$\begin{array}{l}\text { Sat- } \\
\text { ura- } \\
\text { tion } \\
\left(R_{d}\right), \\
\mathrm{ml} / \mathrm{g}\end{array}$} & \multirow{3}{*}{$\begin{array}{c}\text { Sorp- } \\
\text { tion } \\
\text { energy } \\
\mathrm{kJ} / \mathrm{mo}\end{array}$} \\
\hline & & \multicolumn{2}{|c|}{ Freundlich, $\mathrm{mol} / \mathrm{kJ}^{2}$} & \multicolumn{2}{|c|}{ Dubinin-Raduskevich, mol/kg } & & \\
\hline & & $\mathrm{N}$ & K & $\mathrm{C}_{\mathrm{s}}^{\circ}$ & k & & \\
\hline $\mathrm{Sr}^{2+}$ & Kaolinite & 0.91 & 29 & $9.82 \cdot 10^{-4}$ & $6.97 \cdot 10^{-3}$ & 113 & 8.6 \\
\hline $\mathrm{Sr}^{2+}$ & Bentonite & 1.06 & 2576 & $1.40 \cdot 10^{-3}$ & $5.69 \cdot 10^{-3}$ & 1022 & 9.4 \\
\hline $\mathrm{Ba}^{2+}$ & Kaolinite & 0.97 & 118 & $1.19 \cdot 10^{-4}$ & $5.38 \cdot 10^{-3}$ & 170 & 9.6 \\
\hline $\mathrm{Ba}^{2+}$ & Bentonite & 1.03 & 325 & $2.20 \cdot 10^{-4}$ & $5.20 \cdot 10^{-3}$ & 454 & 9.9 \\
\hline $\mathrm{Ba}^{2+}$ & Chlorite - illite & 0.89 & 98.5 & $8.0 \cdot 10^{-4}$ & $4.95 \cdot 10^{-3}$ & 745 & 10.1 \\
\hline
\end{tabular}

In a detailed study of the sorption process, chlorite-illite mixed clay was saturated with $\mathrm{K}^{+}, \mathrm{Sr}^{2+}, \mathrm{Ca}^{2+}$ and $\mathrm{Al}^{3+}$ ions. The sorption solution was deionized water containing only $\mathrm{Ba}^{2+}$ ion at various initial concentrations. For such one to one exchanging systems, any deviation from the expected linear isotherm behavior would indicate the existence of different sorption sites. Indeed all isotherms shown in Fig. 1 were found to be nonlinear with slopes, $N$, varying from 0.79 to 0.93 . The initial parts of both $\mathrm{K}^{+}$and $\mathrm{Ca}^{2+}$ had saturated chlorite-illite isotherms, however, both had a slope of 1.0 indicating linear sorption behavior in the lower concentration regions.

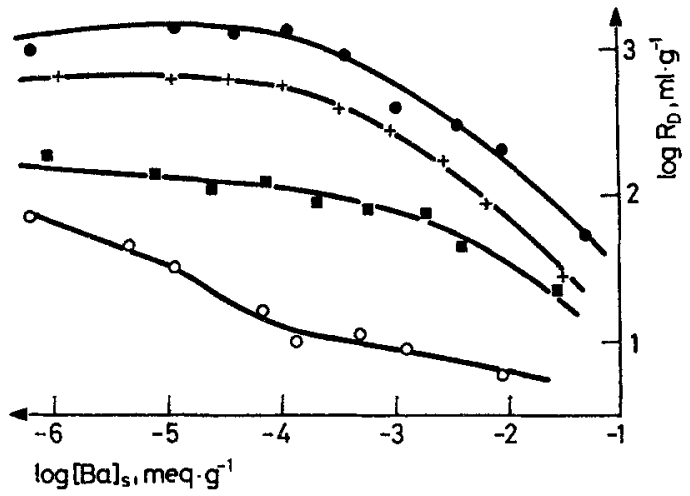

Fig. 2. The variation of the distribution ratio, $R_{d}$, with $\mathrm{Ba}^{2+}$ ion loading for chlorits "lite mixed clay; 3 K-saturated chlorite-illite, + Ca-saturated chlorite-illite, E Sr-saturand chlorite-illite, O Al-saturated chlorite-illite

The maximum uptake of $\mathrm{Ba}^{2+}$ in these experiments corresponded to $33 \%$ of the total CEC of chlorite-illite clay. The corresponding loading curves, i.e., plots of $R_{d}$ against equilibrium concentration of $\mathrm{Ba}^{2+}$ ion on chlorite-illite, are shown in Fig. 2. It is seen that up to a loading of about $1.0 \cdot 10^{-4} \mathrm{meq} / \mathrm{g}$ the $R_{d}$ 's are constant for $\mathrm{K}^{+}, \mathrm{Ca}^{2+}$ and to 
Table 3

Saturation distribution ratios, $R_{d}$, of $\mathrm{K}^{+}, \mathrm{Ca}^{2+}, \mathrm{Sr}^{2+}$ and $\mathrm{Al}^{3+}$ saturated chlorite - illite mixed clay. The shaking time

was 8 days. The initial $\mathrm{Ba}^{2+}$ ion concentration in solution

was $1.56 \cdot 10^{-8} \mathrm{meq} / \mathrm{ml}$. Bidistilled, deionized water was used

\begin{tabular}{lc}
\hline \multicolumn{1}{c}{ Matrix } & Saturation $\left(R_{d}\right), \mathrm{ml} / \mathrm{g}$ \\
\hline K-chlorite - illite & 956 \\
Ca-chlorite - illite & 637 \\
Sr-chlorite - illite & 182 \\
Al-chlorite - illite & 69 \\
Natural chlorite - illite* & 745 \\
\hline
\end{tabular}

*Synthetic groundwater was used in sorption experiments.

Table 4

The variation of $R_{d}$ with $V / M$ for the sorption of $\mathrm{Ba}^{2+}$ on chlorite - illite mixed clay. The initial $\mathrm{Ba}^{2+}$ concentration was $1.53 \cdot 10^{-8} \mathrm{meq} / \mathrm{ml}$. Synthetic groundwater was used and sorption time was 8 days

\begin{tabular}{cc}
\hline$V / M, \mathrm{ml} / \mathrm{g}$ & Saturation $\left(R_{d}\right), \mathrm{ml} / \mathrm{g}$ \\
\hline 10 & 149 \\
40 & 312 \\
80 & 556 \\
200 & 524 \\
\hline
\end{tabular}

some extent $\mathrm{Sr}^{2+}$ saturated chlorite-illite. These regions correspond to the linear isotherm regions of Fig. 1. Beyond $1.0 \cdot 10^{-4} \mathrm{meq} / \mathrm{g}$ loading the $R_{d}$ values drop substantially with increasing loading. Highest $R_{d}$ values, indicating easiest exchange was observed for $\mathrm{K}^{+}$-chlorite-illite and the lowest values corresponding to least exchange for $\mathrm{Al}^{3+}$-chlorite-illite.

The sorption results of $\mathrm{Ba}^{2+}$ ion on natural chlorite-illite were very similar to those of $\mathrm{Ca}^{2+}$ saturated chlorite-illite. Both the sorption isotherms as well as the $R_{d}$ values given in Table 3 were similar. These results indicate that in natural systems $\mathrm{Ba}^{2+}$ in solution exchanges primarily with the $\mathrm{Ca}^{2+}$ ion on the clay mineral.

Another factor in sorption studies is the variation of the distribution ratio $R_{d}$ with aqueous volume to sclid mass $(V / M)$ ratio. Since $R_{d}$ is a function of the concentration of the sorbed species in the solid and liquid phases, it should not be affected by the $V / M$ changes. The results of the variation of $R_{d}$ with $V / M$ for the sorption of $\mathrm{Ba}^{2+}$ ion on chlorite-illite mixed clay are given in Table 4. 
Under experimental conditions given in Table 4 it is seen that $R_{d}$ increases with increasing $V / M$ until a saturation value is reached.

Increasing the $V / M$ ratio disperses the solid particles and exposes them better to the solute ions in solution, resulting in increasing sorption sites. In a recent study MEIR et al. ${ }^{10}$ pointed out that the amount of radionuclide sorbed is related to the mass $M$ of the solid sorbing phase by the relation;

$$
[\mathrm{Ba}]_{s}=[\mathrm{Ba}]_{s}^{0} M
$$

where $[\mathrm{Ba}]_{s}-$ concentration of the sorbed ion in the solid matrix (meq/g),

$[\mathrm{Ba}]_{s}^{0}-$ sorbed concentration when $M=1$,

$M$ - mass of the solid matrix $(\mathrm{g})$,

$\alpha-$ a constant.

Figure 3 shows the application of Eq. (5) for the sorption of $\mathrm{Ba}^{2+}$ ion on chlorite-illite mixed clay at various initial $\mathrm{Ba}^{2+}$ ion concentrations. It is seen that this relationship is very well satisfied over a wide range of initial concentrations.

Between the initial $\mathrm{Ba}^{2+}$ ion concentration ranges of $1.56 \cdot 10^{-8} \mathrm{meq} / \mathrm{ml}$ to 5.0 . $\cdot 10^{-5} \mathrm{meq} / \mathrm{ml}$ the slopes of the curves are equal and around -1 . With increasing initial concentration in going from $1.53 \cdot 10^{-4} \mathrm{meq} / \mathrm{ml}$ to $1.53 \cdot 10^{-3} \mathrm{meq} / \mathrm{ml}$, the slope gradually decreases and tends toward zero. When the slope becomes zero, $[\mathrm{Ba}]_{s}$ does not vary with mass $M$ anymore and becomes equal to $[\mathrm{Ba}]_{s}^{0}$. Under these conditions the solid matrix may be assumed to be saturated with the sorbed cation. The magnitude of $[\mathrm{Ba}]_{s}^{0}$ at this point may be taken to be a measure of the CEC of the clay sample.

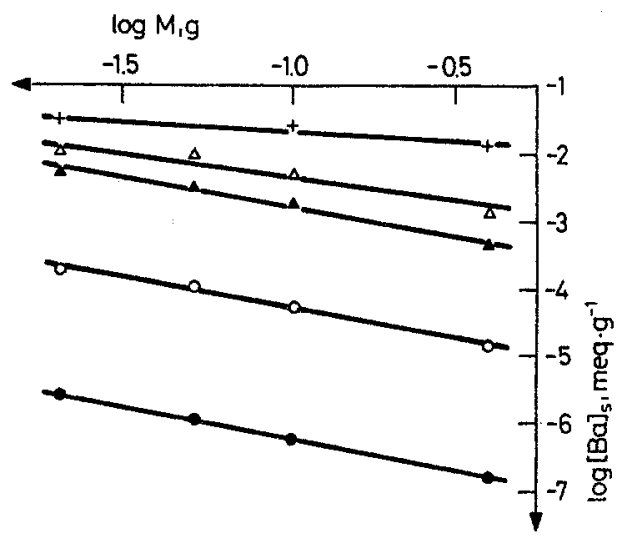

Fig. 3. The change of the adsorbed concentration on the solid matrix $[\mathrm{Ba}]_{s}$ as a function of solid mass $M$, for the sorption of $\mathrm{Ba}^{2+}$ ion on chlorite-illite mixed clay, for different initial $\mathrm{Ba}^{2+}$ concentrations, $[\mathrm{Ba}]_{l}$; - $[\mathrm{Ba}]_{l}^{0}=1.56 \cdot 10^{-8} \mathrm{meq} / \mathrm{ml}, O[\mathrm{Ba}]_{l}^{0}=1.53 \cdot 10^{-6} \mathrm{meq} / \mathrm{ml}, \triangle[\mathrm{Ba}]_{l}^{0}=5.0 \cdot 10^{-5} \mathrm{meq} / \mathrm{ml}, \Delta[\mathrm{Ba}]_{l}^{0}=$ $=1.53 \cdot 10^{-4} \mathrm{meq} / \mathrm{ml},+[\mathrm{Ba}]_{l}^{0}=1.53 \cdot 10^{-3} \mathrm{meq} / \mathrm{ml}$ 
Table 5

The variation of the distribution coefficients with $\mathrm{pH}$ for the sorption of $\mathrm{Ba}^{2+}$ and $\mathrm{Sr}^{2+}$ ions on clays.

The initial concentration of $\mathrm{Ba}^{2+}$ ion was $1.56 \cdot 10^{-8} \mathrm{meq} / \mathrm{ml}$ and $\mathrm{Sr}^{2+}$ was $5.71 \cdot 10^{-8} \mathrm{meq} / \mathrm{ml}$

\begin{tabular}{lcrrrrrrc}
\hline & & \multicolumn{6}{c}{$R_{d}, \mathrm{~g} / \mathrm{ml}$ at various $\mathrm{pH}$ values } \\
\cline { 3 - 8 } Solid matrix & Sorbed ion & 1.6 & 3.0 & 5.0 & 8.5 & 11.0 & 13.5 \\
\cline { 3 - 8 } & & - & 63 & 57 & 66 & 119 & - \\
Kaolinite & $\mathrm{Ba}^{2+}$ & - & 837 & 780 & 454 & 1080 & - \\
Bentonite & $\mathrm{Ba}^{2+}$ & - & 388 & 434 & 461 & 461 & - \\
Chlorite - illite & $\mathrm{Ba}^{2+}$ & - & 50 & 1300 & 1800 & 1259 & 832 & 1905 \\
Bentonite & $\mathrm{Sr}^{2+}$ & & & &
\end{tabular}

The effect of $\mathrm{pH}$ on the sorption process was also studied. Sorption experiments were carried out at various $\mathrm{pH}$ values. The $\mathrm{pH}$ of the aqueous solutions, following pretreatment, were adjusted by using appropriate $\mathrm{HCl}$ and $\mathrm{NaOH}$ solutions. The results are given in Table 5 .

No significant change in the sorption behavior of $\mathrm{Ba}^{2+}$ and $\mathrm{Sr}^{2+}$ is observed between the $\mathrm{pH}$ range of 3.0-8.5. For kaolinite and bentonite at $\mathrm{pH}$ of 11.0 and above, the $R_{d}$ values increase, probably due to the formation of carbonate complexes.

\section{References}

1. A. GRUTTER, H. R. VON GUNTEN, E. ROESSLER, Clay clay Min., 34 (1986) 677.

2. E. BROUWER, B. BAEYENS, A. CRAMERS, J. Phys. Chem., 87 (1986) 1213.

3. B. TORSTENFELT, Radiochim. Acta, 39 (1986) 97.

4. K. H. LIESER, B. GLEITSMANN, TH. STEINKOPF, Radiochim. Acta, 40 (1986) 33.

5. K. H. LIESER, TH. STEINKOPF, Radiochim. Acta, 46 (1989) 39.

6. H. N. ERTEN, F. AKSOYOGLU, H. GÖKTÜRK, The Sci. Tot. Envir., 69 (1988) 269.

7. P. WARWICK, A. HALL, P. SHAW, Radiochim. Acta, $52 / 53$ (1991) 465.

8. W. R. ALEXANDER, R. D. SCOTT, A. B. MAC KENZIE, I. G. McKINLEY, Radiochim. Acta, 44/45 (1988) 283.

9.. T. E. ERICKSEN, Nucl. Tech., 70 (1985) 261.

10. H. MEIER, E. ZIMMERHACKL, G. ZEITLER, P. MENGE, W. HECKER, J. Radioanal. Nucl. Chem., 109 (1987) 139.

11. I. GRENTHE, Radiochim. Acta, 52/53 (1991) 425 .

12. P. L. SEARLE, Aust. J. Soil. Res., 24 (1986) 193.

13. I. LANGMUIR, J. Am. Chem. Soc., 40 (1918) 1361.

14. H. FREUNDLICH, Colloid and Capillary Chemistry, Methuen, London, 1926.

15. M. M. DUBININ, L. V. RADUSHKEVICH, Proc. Acad. Sci. Phys. Chem. Sec. USSR, 55 (1947) 331. 